\title{
An integrated analysis of miRNA and gene copy numbers in xenografts of Ewing's sarcoma
}

\author{
Neda Mosakhani ${ }^{1 \dagger}$, Mohamed Guled ${ }^{1}$, Gayle Leen², Silvia Calabuig-Fariñas ${ }^{3}$, Tarja Niini ${ }^{1}$, Isidro Machado³, \\ Suvi Savola ${ }^{1}$, Katia Scotlandi ${ }^{4}$, José Antonio López-Guerrero ${ }^{5}$, Antonio Llombart-Bosch ${ }^{3}$ and Sakari Knuutila ${ }^{{ }^{*}}$
}

\begin{abstract}
Background: Xenografts have been shown to provide a suitable source of tumor tissue for molecular analysis in the absence of primary tumor material. We utilized ES xenograft series for integrated microarray analyses to identify novel biomarkers.
\end{abstract}

Method: Microarray technology (array comparative genomic hybridization (aCGH) and micro RNA arrays) was used to screen and identify copy number changes and differentially expressed miRNAs of 34 and 14 passages, respectively. Incubated cells used for xenografting (Passage 0 ) were considered to represent the primary tumor. Four important differentially expressed miRNAs (miR-31, miR-31*, miR-145, miR-106) were selected for further validation by real time polymerase chain reaction (RT-PCR). Integrated analysis of aCGH and miRNA data was performed on 14 xenograft passages by bioinformatic methods.

Results: The most frequent losses and gains of DNA copy number were detected at 9p21.3, 16q and at 8, 15, 17q21.32-qter, 1q21.1-qter, respectively. The presence of these alterations was consistent in all tumor passages. aCGH profiles of xenograft passages of each series resembled their corresponding primary tumors (passage 0). MiR21, miR-31, miR-31*, miR-106b, miR-145, miR-150*, miR-371-5p, miR-557 and miR-598 showed recurrently altered expression. These miRNAS were predicted to regulate many ES-associated genes, such as genes of the IGF1 pathway, EWSR1, FLI1 and their fusion gene (EWS-FL11). Twenty differentially expressed miRNAs were pinpointed in regions carrying altered copy numbers.

Conclusion: In the present study, ES xenografts were successfully applied for integrated microarray analyses. Our findings showed expression changes of miRNAs that were predicted to regulate many ES associated genes, such as IGF1 pathway genes, FLI1, EWSR1, and the EWS-FLI1 fusion genes.

Keywords: Ewing's sarcoma xenograft, MicroRNA, Copy number, Microarray

\section{Background}

Due to active international collaboration in the study of rare tumors, such as in Ewing's sarcoma (ES), a great body of tumor-related molecular biomarkers have already been mined by novel array technologies and the clinical significance of some of the biomarkers has been established [1]. A limiting factor for the research of rare bone tumors has been the limited availability of research material derived from patients. Therefore, xenografts,

\footnotetext{
*Correspondence: sakari.knuutila@helsinki.fi

+ Contributed equally

'Department of Pathology, Haartman Institute and HUSLAB, University of

Helsinki and Helsinki University Central Hospital, Helsinki, Finland

Full list of author information is available at the end of the article
}

tumors grown from human tumor cells and implanted in immunodeficient animals, are a viable option that is widely used for in vivo models [2,3]. Xenografted tumors are enriched for neoplastic cells with the minimal contaminating mouse stromal tissue, a property that makes them suitable for molecular analysis [4]. Several studies have shown that xenograft tumors may provide an accurate reflection of tumor biology [5-9].

MicroRNAs (miRNAs) are small, single-stranded noncoding endogenous RNAs, consisting of 20-23 nucleotides, typically acting as post-transcriptional repressors $[10,11]$. Despite the fact that miRNAs have been implicated in more than 70 diseases, they have never been

\section{Biomed Central}


investigated, to our knowledge, in the tumor/xenograft setting [12] (http://cmbi.bjmu.edu.cn/hmdd).

Here, we have performed miRNA- and comparative genomic hybridization $(\mathrm{CGH})$ array analyses on a series of ES xenografts to investigate differential miRNA expression and genomic DNA copy number changes, which are potentially involved in the tumorigenesis of ES. These results have been assessed to identify whether copy number alterations influence miRNA expression, since DNA copy number abnormalities can have a direct impact on the miRNA expression levels [13]. Multiple xenograft passages from each primary tumor were tested to enhance the statistical power of the study.

\section{Methods}

\section{Samples}

Originally six xenograft series originating from ES patients (5 primary tumors and a lung metastasis) comprising 34 passages in total were obtained from the Department of Pathology, University of Valencia, Spain. Two series of xenograft passages originated from one patient with both the primary tumor and the metastatic tumor in the lung. Although all of the 34 passages were used in the aCGH study, only 14 out the 34 passages were available for the miRNA study (Table 1). These 14 passages represented original 5 xenograft series, including both early and advanced passages. The passage 0 that represented primary tumor and was available for four series of the xenografts was not, however, available for miRNA profiling. The EWS-FLI1 and EWS-FEV translocations were present in 4 and 1 of the primary tumors, respectively, and were retained in all xenografts. To select an optimum control for any kind of expression analysis is generally considered a difficult task; we ended up with two human mesenchymal stem cell samples from different cell cultures for use as controls. Mesenchymal stem cells have been utilized as control samples in many previous expression studies due to the convincing evidence that supports the mesenchymal stem cell origin of ES [13-15]. DNA microarray analysis,

Table 1 Ewing sarcoma xenograft series, 6, originating from five patients

\begin{tabular}{ll}
\hline Case No. (Nude) & Xenograft Passage \\
\hline $488(15)$ & $1^{*}, 2^{*}, 4,7^{*}, 11,14^{*}$ \\
$445(22)$ & $0,1,4,11,15,22$ \\
$451(53)$ & $0,4,11^{*}, 15^{*}, 18,21^{*}$ \\
$455(199)$ & $0,1,5^{*}, 11,17,25^{*}$ \\
$430($ PRI) (230) & $0,1^{*}, 4,9,19^{*}$ \\
430 (MET) (248) & $1^{*}, 4,14^{*}, 21,30^{*}$ \\
\hline
\end{tabular}

Case number 430 has two xenograft passages originating from one patient in different status of tumor: PRI = Primary Tumor, MET = Lung Metastasis.

Samples used in the miRNA study are marked with an asterisk. Xenograft passage number 0 refers to the corresponding primary patient sample as well as functional studies, have revealed the relationship between ES and mesenchymal stem cells $[16,17]$ as well as between ES and endothelium, and fetal neural crest $[18,19]$, further sustaining the fact that, despite all the efforts, the origin of ES is still a matter of dispute. Very likely ES derives from much undifferentiated cells. In our analysis, we used mesenchymal stem cell as the calibrator, in analogy to other reports recently published $[20,21]$.

The stem cells were obtained from human primary bone marrow-derived mesenchymal stem cells after informed patient consent; precisely, from bone marrow aspirates (iliac crest) of patients undergoing hip replacement surgery. Nucleated cells were placed in modified alpha-MEM media (Li StarFish) containing 20\% fetal bovine serum (Cambrex Bioscience), 100 units $/ \mathrm{mL}$ penicillin (Life Technologies), $100 \mathrm{mg} / \mathrm{mL}$ streptomycin (Life Technologies), and $2 \mathrm{mmol} / \mathrm{L}$ glutamax (Life Technologies). Confluent cells were harvested by trypsin/EDTA and seeded at 1:3 density.

\section{Xenografts}

Male nude mice were purchased from IFFA-CREDO (Lyon, France) and kept under specific pathogen-free conditions throughout the experiment (with vinyl isolates plus sterilized food, water, cage, and bedding). The specimens for xenografting were obtained from the surgery of original tumors and placed in the culture medium (RPMI 1640) with antibiotics at $37^{\circ} \mathrm{C}$ until the transplantation (usually less than 2 hours after the surgery). Various fragments of the non-necrotic tumor, about 3-5 $\mathrm{mm}$ in size, were xenografted into the subcutaneous tissue of the backs of nude mice. The cells from this first implantation are denoted as passage 0 cells and are considered to represent primary tumors. After allowing the growth to approximately $2-3 \mathrm{~cm}$, the subsequent tumor transfers were performed following the same procedures as in the initial xenotransplant and always under highly sterile conditions. In each passage, sufficient amount of material was obtained for the histopathology analysis (Formalin-fixed paraffin-embedded tissue blocks from which tissue microarrays were constructed), the touch preparations, the electron microscopy, the tissue culture, and frozen tissue. All the experimentation involving laboratory animals was approved by the Institutional Animal Care of Valencia University and the Local Government and was performed in accordance with the national legislation of Spain.

The ploidy analysis was not seen necessary to be performed as both histopathological and copy number analysis did not provide any evidence of polyploidy.

\section{Nucleic acid isolation}

Genomic DNA from the 34 passages (Table 1) was extracted by the standard phenol-chloroform method. 
Reference DNAs, male and female, were extracted from the pooled blood samples (4 individuals each) obtained from the Blood Service, Red Cross, Finland. The Qiagen's miRNeasy Mini Kit (Qiagen, Valencia, CA, USA) was used to extract total RNA, including miRNA, according to the manufacturer's instructions. The Nanodrop-1000 spectrophotometer (Thermo Fisher Scientific Inc., Wilmington, DE, USA) was used for quantification of DNA and RNA. The quality of DNA was checked by gel electrophoresis, while for the quality of total RNA and miRNA, the Agilent bioanalyzer (Agilent Technologies, Santa Clara, CA, USA) was applied.

\section{Array CGH hybridization, scanning and data analysis} The Agilent Human Genome CGH 4x44A oligo microarrays (Agilent Technologies, Santa Clara, CA, USA) containing $\sim 44,000$ oligonucleotide probes were used. Digestion, labeling, and hybridization of DNA were done according to the manufacturer's instructions (Agilent protocol version 2.0). Briefly, the same amounts $(1.5 \mu \mathrm{g})$ of patient DNA and gender matched reference DNA were digested. The digested DNAs were labelled by random priming with Cy3-dUTP (reference DNA) and Cy5-dUTP (patient DNA) by use of the Agilent Labelling Kit, after which the labelled DNAs were purified. Next, differentially labelled patient and reference DNAs were combined and hybridized to Agilent Human Genome CGH $4 \times 44 \mathrm{~A}$ microarrays at $65^{\circ} \mathrm{C}$ for 24 hours. The hybridized arrays were washed and, then, scanned with the Agilent's microarray scanner (G2565BA, Agilent Technologies, Santa Clara, CA, USA). The raw data was extracted from the array images by the Agilent's Feature Extraction Software (version 8.1). The data was analyzed with the Agilent CGH Analytics software (version 3.4) using ADM-2 algorithm (threshold 6.0) with 1.0 Mb window size.

\section{MicroRNA hybridization, scanning and data processing}

We used the Agilent's miRNA microarray system (V3), containing 866 human and 89 human viral miRNAs catalogued in the Sanger miRNA database v12 (Agilent Technologies, Santa Clara, CA, USA). Labelling and hybridization of RNA samples was performed with the Agilent's miRNA Complete Labelling and Hyb Kit. Accordingly, $100 \mathrm{ng}$ of total RNA were treated with Calf Intestine Phosphatase for $30 \mathrm{~min}$ at $37^{\circ} \mathrm{C} ; 100 \% \mathrm{DMSO}$ was used for denaturation at $100^{\circ} \mathrm{C}$ for $5 \mathrm{~min}$, after which the samples were immediately transferred into an ice water bath to prevent reannealing. Next, samples were labelled with cyanine 3-pCp by incubating with T4 RNA ligase for 2 hours at $16^{\circ} \mathrm{C}$. After the labeling reaction, the samples were vacuum dried at medium heat and re-suspended in nuclease-free water. Next, samples were hybridized to the microarrays in the Agilent SureHyb chambers (Agilent Technologies) for 20 hours at $55^{\circ} \mathrm{C}$, after which the microarrays were washed with the manufacturer's washing buffers. The arrays were scanned using the Agilent's scanner and the raw data were preprocessed with the Agilent's Feature Extraction Software with default parameters. Details of the miRNA preprocessing protocol are provided by the manufacturer.

Statistical analysis was carried out with the GeneSpring GX analysis software (version 10) and the R statistical programming language (http://www.r-project. org). The data were preprocessed by adding offsets and carrying out normalization between all the arrays by the quantile method, and taking $\log 2$ transformation. The data were filtered by removing control miRNAs and the miRNAs that were not detected across any of the samples. Detection calls were provided by the Agilent's Feature Extraction Software. MiRNAs with less than the threshold of the ratio of total gene signal/total gene error under three were considered to be undetected. The detected miRNAs were regarded as present in the measured sample. We also removed miRNAs based on their expression: for each miRNA, its expression had to exceed in at least one array (negative control miRNAs' expression) $+1.5 \times$ standard deviation (negative control miRNAs' expression). We examined the detection calls for each sample to determine which miRNAs were expressed or not expressed. To find differentially expressed miRNAs between controls and xenograft samples, we performed moderated t-tests for each miRNA to find significant differences in miRNA expression between the two groups and, then, calculated the most significant up-regulated and downregulated miRNAs (adjusted $\mathrm{p}$ value $[\mathrm{q}$ value] $<0.05$, Bonferroni correction to correct for multiple testing).

\section{Real-time polymerase chain reaction (real-time RT-PCR) analysis}

To validate the selected miRNA expression levels in ES samples compared to control samples, RT-PCR analysis was applied. The miScript Reverse Transcription Kit (Qiagen, Valencia, CA) served for reverse transcription of RNA, according to manufacturer's guidelines. QRTPCR was performed on a Light-cycler, software v.3.5 (Roche Applied Science, Mannheim, Germany) by the SYBR Green miScript PCR system (Qiagen). Each reaction was performed in a $20-\mu \mathrm{l}$ volume with $5 \mathrm{ng}$ template cDNA. The primers for amplification of selected miRNAs and snRNA U6 were purchased from the Qiagen. The experiments were performed in duplicate for each RNA sample, and every run included a control without template. The U6 primer assay (Qiagen) served as an endogenous control for normalization. The relative quantification (RQ) for each miRNA, compared with U6 was calculated using equation $2^{-\Delta \Delta \mathrm{C} t}$. 
Relationship between miRNA and CGH data

We investigated whether any association existed between miRNA expression changes and gain/loss of genomic regions. We mapped each miRNA to its chromosomal band location, which was retrieved from the Ensembl, using the biomaRt package, and the mirBase database. For each miRNA, we counted the number of xenograft samples (out of 14) in which there was loss, gain, or no change in copy number for the corresponding chromosomal band. Possible associations were determined by counting the number of samples showing miRNA over-expressed/genomic gain and miRNA under-expressed/genomic loss. We also counted the number of control samples (out of 2) in which the miRNA was detected.

\section{Predicted targets of differentially expressed miRNAs}

After having acquired the differentially expressed miRNAs, we used the miRBase target prediction database (http://microrna.sanger.ac.uk), TargetScan (http://www. targetscan.org), and miRanda (http://www.microRNA. org) for evaluation of the predicted mRNA targets. The list of predicted mRNA targets was screened for the genes known to be functionally relevant in ES and predicted at least by one of the algorithms.

\section{Results}

\section{Copy number alterations in xenografts}

By the aCGH analysis, xenograft passages displayed a total of 28 copy number changes, of which approximately half appeared in every passage of each series whilst the other half were present in some of the passages of each series (Table 2, and 3). All these changes were evident in passage 0 . Moreover, the clustering analysis of aCGH profiles for each cytogenetic location indicated that the aCGH profiles of the passages 0 as primary tumors and the rest of the xenograft passages were similar (Figure 1). Copy number losses (65\%) were more frequent than gains $(35 \%)$. The most frequent copy number losses were seen at chromosomal regions 9p21.3 and 16q; these were observed in four (63\%) and two $(20 \%)$ series of xenografts passages, respectively.

Table 2 The copy number changes present in all the passages of each xenograft series

\begin{tabular}{ll}
\hline Case No. (Nude) & Array CGH results \\
\hline $488(15)$ & $+1 q 21.1-q t e r,-13 q 14.12-q t e r$ \\
$445(22)$ & $-2 q 35-q 37.3$ (uncontinuous), + 8, +15, +17q21.32-qter \\
$451(53)$ & $-1 q 24.3-q 25.2,-3 p 12.3-p 24.3,-9 p 21.3$ \\
$455(199)$ & $+1 q,-16 q,-9 p 21.3$ \\
$430($ PRI) (230) & $-9 p 21.3$ \\
$430($ MET) (248) & $-1 p 36.12-p t e r,-9 p 21.3$ \\
\hline
\end{tabular}

$\mathrm{PRI}=$ Primary Tumor, MET = Lung Metastasis
Table 3 Copy number changes present in only part of the passages of each xenograft series

\begin{tabular}{lll}
\hline Case & Nude- Passage & Array CGH result \\
\hline 488 & $15-2,4,7,11,14$ & $-2 q 35-q 37.3$ \\
488 & $15-1,2,4,7$ & $-17 q 12-q 21.32$ \\
488 & $15-14$ & +17 \\
451 & $53-11,15,18,21$ & $+4 q 13.3-q$ ter, $-17 p$ \\
455 & $199-5,11,17,25$ & -13 \\
455 & $199-25$ & $-X q 21.1$ \\
430 (PRI) & $230-1,4,9,19$ & $+8 p 11.21-p 21.2,+8 q$ \\
430 (MET) & $248-1,4$ & $-1 p 36.12-p t e r$ \\
430 (MET) & $248-14,21,30$ & $-1 p 36.21-p t e r,-1 p 13.3-p 31.1,-5 q$, \\
& & $-11 q 13.4-q 24.3,-X q 12-q 26.3$ \\
430 (MET) & $248-21,30$ & $+8 p 11.21-p 21.2,+8 q$ \\
430 (MET) & $248-30$ & $-16 q$
\end{tabular}

$\mathrm{PRI}=$ Primary Tumor, MET = Lung Metastasis

The frequent gain at whole chromosomes 8 and 15 (17\%) occurring together with a gain at 17q21.32-qter (17\%) was observable in all passages of a series (case number 445). The genomic region 1q21.1-qter frequently displayed gain. Changes in copy number were acquired during the growth period of xenografts including gains at 2q35-q37.3, 4q13.3-qter, 8p11.21-p21.2 and $8 \mathrm{q}$ and losses at $8 \mathrm{p}, 17 \mathrm{p}, 13, \mathrm{Xq21.1}, 1 \mathrm{p} 13.3-\mathrm{p} 31.1,5 \mathrm{q}$, 11q13.4-q24.3, Xq12-q26.3 and 16q. In one xenograft series (Case number 488), loss of $17 \mathrm{q} 12-\mathrm{q} 21.32$, that was present in the early passages, disappeared during the growth process. The loss of 1p36.12-pter in the first two passages originating from lung metastasis ( 1 and 4 ) changed to loss of 1 p36.21-pter in the last three passages $(14,21$, and 30$)$. The lung metastasis xenografts showed 9 copy number changes, whereas only 3 of these aberrations were observable in the xenograft passages from its primary tumor.

\section{MicroRNA alterations in xenografts}

Differences in miRNA expression between xenografts and control samples were detected upon analysis (Figure 2). Exclusively expressed miRNAs were detected; two in control samples (miR-31, miR-31*) and 46 in all xenograft passages (Table 4). In addition, 5 miRNAs (miR-106b, miR-93, miR-181b, miR-101, miR-30b) were significantly over-expressed (q-value $<0.05)$, while 6 miRNAs (miR145, miR-193a-3p, miR-100, miR-22, miR-21, miR-574-3p) were significantly under-expressed across the xenograft passages in relation to the controls (q-value $<0.05)$. Xenografts from primary and control samples were compared to xenograft passages from the lung metastasis (Case number 430), to determine differences in miRNA expression. A set of 30 miRNAs were found to have differential expression; 18 exclusively expressed in lung metastatics xenografts and 12 in primary tumor xenografts. 

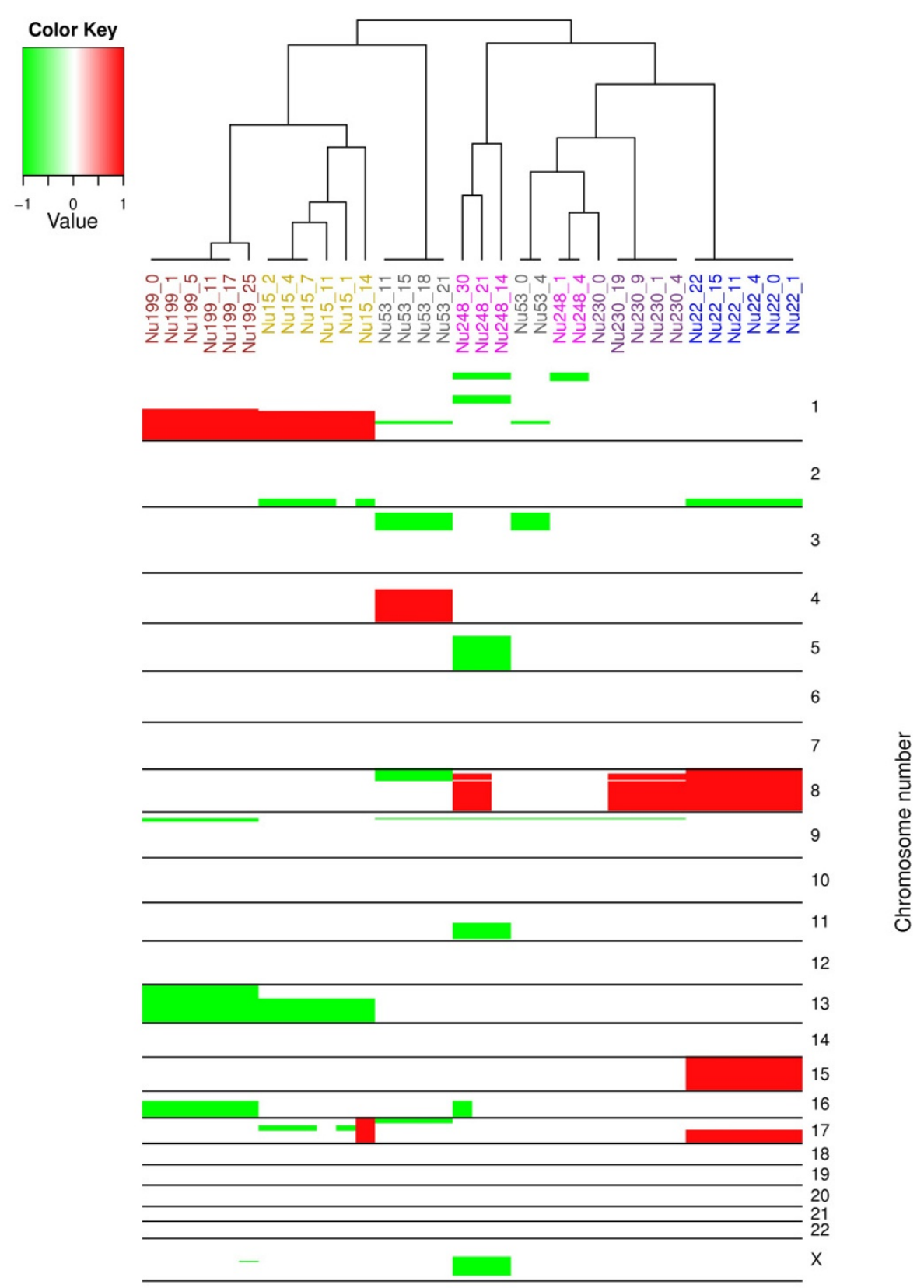

Xenograft passage samples

Figure 1 Copy number changes on each chromosome were ordered using hierarchical clustering. Most of the xenograft passages of each series clustered together and also with the passage 0 , its corresponding primary tumor.

Eleven miRNAs were expressed in both control samples and primary tumor xenograft passages but not at all in metastatic samples (Table 5, Figure 3). Nine of these (miR-214*, miR-154*, miR-337-3P, miR-369-5p, miR-409-5p, miR-411, miR-485-3p, miR-487a, miR-770$5 \mathrm{p})$ were also preferentially expressed in other primary tumor xenografts when compared to metastatic xenograft passages.

Validation of differentially expressed miRNAs by qRT-PCR QRT-PCR was used to validate the expression levels of four selected miRNAs that showed altered expression in 

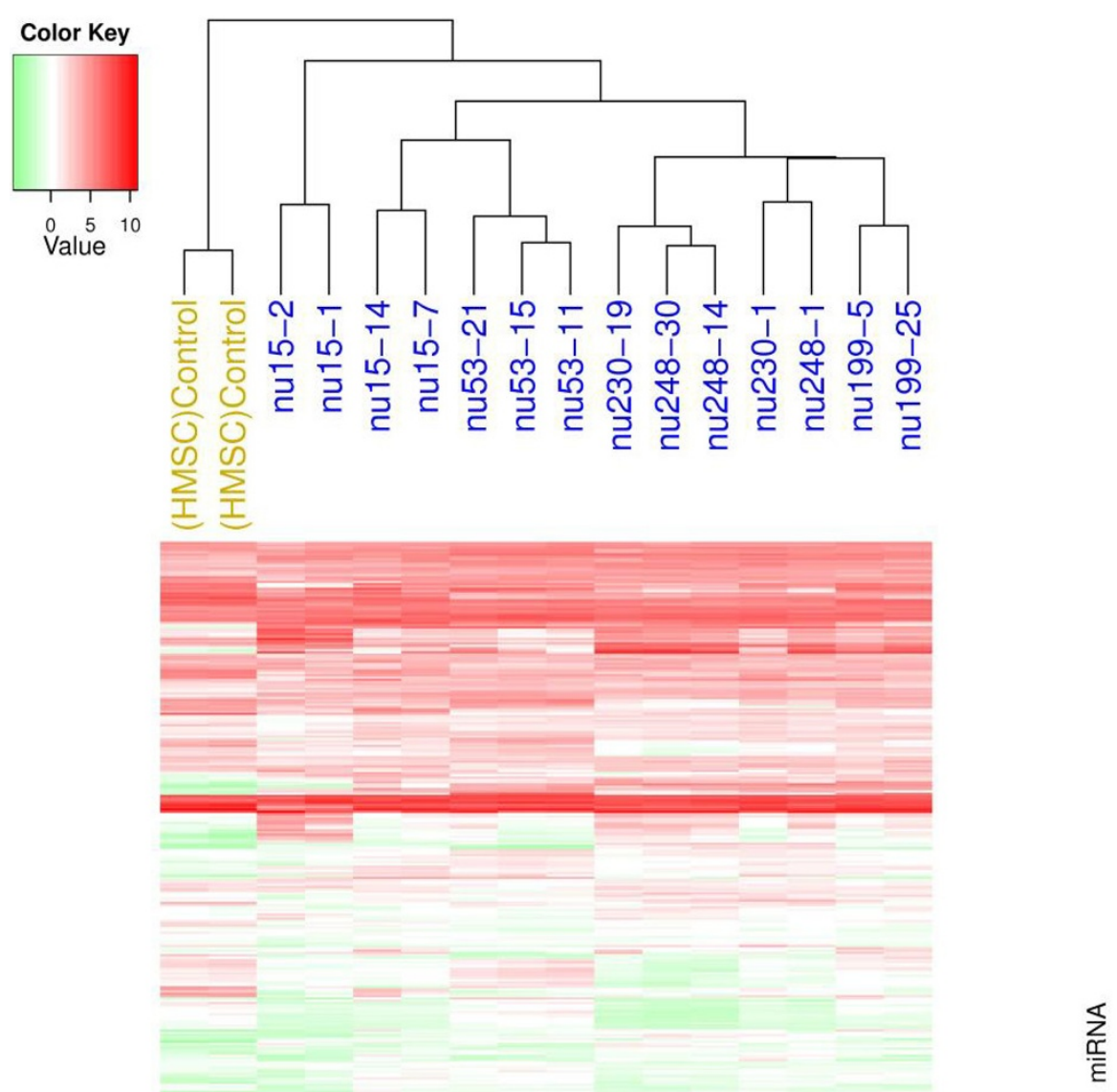

Xenograft passage samples and controls

Figure 2 This picture shows the miRNAs detected in metastasis and corresponding primary tumor xenograft passages and control samples. In common, these three sample types comprised 191 miRNAs. In addition to these, 98 miRNAs were expressed in both the metastasis and the corresponding primary tumor xenograft passages, 22 miRNAs were exclusively expressed in metastatic xenograft passages, 12 miRNAs were exclusive to xenografts from primary tumor, and 11 miRNAs were expressed as well in controls as in primary tumor xenograft passages.

the miRNA microarray results. The selection of miRNAs for further validation was based on the expression level of miRNA microarray results and on the level of representation in the expression categories observed (i.e. exclusively expressed, significantly under-expressed and significantly over-expressed). The miR-31 and miR-31* were exclusively expressed in control samples and absent in xenograft passages, while miR-106b was 
Table 4 The 46 miRNAs detected in all xenografts samples, while absent from all control samples.

\begin{tabular}{llll}
\hline miRNA & miRNA & miRNA & miRNA \\
\hline hsa-miR-1224-5p & hsa-miR-451 & hsa-miR-188-5p & hsa-miR-629* \\
hsa-miR-126* & hsa-miR-483-5p & hsa-miR-652 & hsa-miR-663 \\
hsa-miR-1290 & hsa-miR-486-5p & hsa-miR-19b-1* & hsa-miR-7-1* \\
hsa-miR-1300 & hsa-miR-194 & hsa-miR-215 & hsa-miR-744 \\
hsa-miR-135a* & hsa-miR-195* & hsa-miR-219-5p & hsa-miR-877* \\
hsa-miR-142-3p & hsa-miR-501-3p & hsa-miR-873 & hsa-miR-9 \\
hsa-miR-144 & hsa-miR-502-3p & hsa-miR-30c-1* & hsa-miR-9* \\
hsa-miR-150 & hsa-miR-505* & hsa-miR-328 & \\
hsa-miR-150* & hsa-miR-223 & hsa-miR-338-3p & \\
hsa-miR-181 * & hsa-miR-564 & hsa-miR-371-5p & \\
hsa-miR-548c-5p & hsa-miR-421 & hsa-miR-345 & \\
hsa-miR-557 & hsa-miR-339-3p & hsa-miR-378 & \\
hsa-miR-33a & hsa-miR-598 & hsa-miR-629 & \\
\hline
\end{tabular}

significantly over-expressed and miR-145 significantly under-expressed, respectively, in xenograft samples compared to control samples.

As for the validation results by qRT-PCR, the expression levels of miR-31, miR-31* and miR-145 were under-expressed in the xenograft samples compared to the control samples (relative expression 0.00062, 0.00809 and 0.09111 , respectively). These results are consistent with the miRNA microarray results. Similarly, the over-expression of miR-106b in xenograft samples seen in miRNA microarray was confirmed by qRT-PCR results showing relative expression level of 87.7 .

\section{Relationship between miRNAs and copy number} alterations

A joint analysis of the aCGH data and miRNA data for the 14 xenograft passages, which were common to both studies, was performed by looking for miRNAs whose expression was correlated with a change (loss/gain) at their chromosomal location. Three criteria were used to determine the miRNAs of greatest interest: (i) differentially expressed miRNAs in all 14 xenograft passages, (ii) altered miRNAs whose chromosomal locations were affected by the same copy number changes in most of the passages, and (iii) miRNAs fulfilling both previous criteria.

Of the 46 miRNAs exclusively expressed in all xenograft passages, 7 miRNAs (miR-144, miR-195*, miR-215, miR451, miR-454, miR-557, miR-744) were located in chromosomal regions with a copy number gain in at least one of the passages. Four miRNAs that displayed absent or severely reduced expression in any xenograft passages (miR-22, miR-31, miR-31*, miR-145) were located in chromosomal regions with a copy number loss in at least 2 of the passages. In addition, five passages displayed gains of a chromosomal region that contained 3 frequently expressed miRNAs (miR-765, miR-135b and miR-29c*); miR-765 and miR-135b were expressed in 10 passages while miR$29 \mathrm{C}^{*}$ was expressed in 12 passages but in none of the control samples (Table 6).

\section{Discussion}

Here we have sought to identify differentially expressed miRNAs in ES xenografts and to investigate the

Table 5 MiRNAs expressed in xenograft passages of A) Case 430 primary tumor while absent in lung metastasis, 12 miRNAs, B) Case 430 lung metastasis while absent in primary tumor, 18 miRNAs and C) Case 430 primary tumors and control, while absent in lung metastasis, 11 miRNAs

\begin{tabular}{|c|c|c|c|}
\hline \multicolumn{4}{|l|}{ miRNAs expressed in } \\
\hline \multirow{2}{*}{$\begin{array}{l}\text { A) Xenograft passages from Primary tumor ( } 12 \\
\text { miRNAs) } \\
\text { hsa-miR-1237 }\end{array}$} & \multicolumn{2}{|c|}{$\begin{array}{l}\text { B) Xenograft passages } \\
\text { from lung metastasis ( } 18 \\
\text { miRNAs) }\end{array}$} & \multirow{2}{*}{$\begin{array}{l}\text { C) Control and xenograft passages from Primary tumor (11 } \\
\text { miRNAs) } \\
\text { hsa-miR-154* }\end{array}$} \\
\hline & hsa-miR-1183 & hsa-miR-595 & \\
\hline hsa-miR-139-3p & hsa-miR-124 & hsa-miR-601 & hsa-miR-214* \\
\hline hsa-miR-139-5p & hsa-miR-1471 & hsa-miR-623 & hsa-miR-337-3p \\
\hline hsa-miR-202 & hsa-miR-32* & hsa-miR-662 & hsa-miR-34a* \\
\hline hsa-miR-30b* & hsa-miR-424* & hsa-miR-664* & hsa-miR-369-5p \\
\hline hsa-miR-450a & $\begin{array}{l}\text { hsa-miR-486- } \\
3 p\end{array}$ & $\begin{array}{l}\text { hsa-miR-671- } \\
5 p\end{array}$ & hsa-miR-409-5p \\
\hline hsa-miR-490-3p & $\begin{array}{l}\text { hsa-miR- } \\
\text { 520b }\end{array}$ & & hsa-miR-411 \\
\hline hsa-miR-501-5p & hsa-miR-520e & & hsa-miR-485-3p \\
\hline hsa-miR-502-5p & hsa-miR-96 & & hsa-miR-487a \\
\hline hsa-miR-548d-5p & hsa-miR-877 & & hsa-miR-542-3p \\
\hline hsa-miR-602 & hsa-miR-95 & & hsa-miR-770-5p \\
\hline hsa-miR-885-5p & hsa-miR-765 & & \\
\hline
\end{tabular}




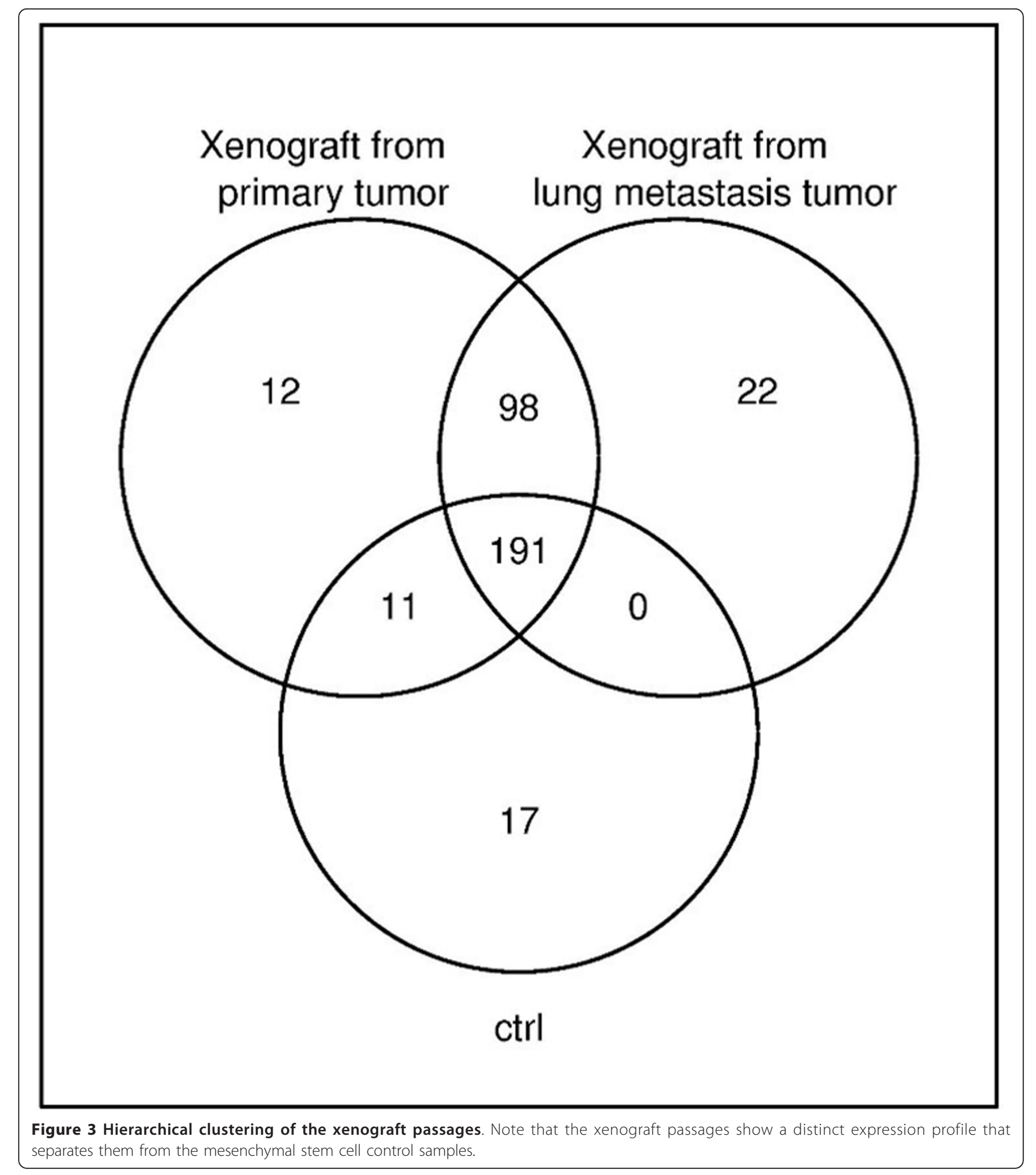

underlying molecular changes by integration of these results with aCGH analysis of the same samples.

MiRNA expression profile of ES xenografts

Xenografts displayed 60 differentially expressed miRNAs that distinguished them from control samples (Human mesenchymal stem cells). Of these, 46 miRNAs were exclusively expressed in xenografts while 2 (miR-31 and miR-31*) miRNAs were exclusively expressed in controls. The remaining 5 miRNAs (miR-106b, miR-93, miR-181b, miR-101, miR-30b) were significantly overexpressed while 6 miRNAs (miR-145, miR-193a-3p, 
Table 6 Altered miRNAs in regions of copy number changes

\begin{tabular}{|c|c|c|c|c|c|}
\hline \multicolumn{3}{|c|}{ miRNA in copy number gain } & \multicolumn{3}{|c|}{ miRNA in copy number loss } \\
\hline miRNA & $\begin{array}{l}\text { Chr. } \\
\text { location }\end{array}$ & $\begin{array}{l}\text { Number of samples } \\
\text { in gain region }\end{array}$ & miRNA & $\begin{array}{l}\text { Chr. } \\
\text { location }\end{array}$ & $\begin{array}{l}\text { Number of samples } \\
\text { in loss region }\end{array}$ \\
\hline miR-765 & $1 \mathrm{q} 23.1$ & 5 & miR-137 & $1 \mathrm{p} 21.3$ & 2 \\
\hline miR-135b & $1 \mathrm{q} 32.1$ & 5 & $\operatorname{miR}-143^{*}$ & $5 q 32$ & 2 \\
\hline $\operatorname{miR}-29 c^{*}$ & $1 \mathrm{q} 32.2$ & 5 & $\operatorname{miR}-143^{*}$ & $5 q 32$ & 2 \\
\hline miR-557 & $1 \mathrm{q} 24.2$ & 6 & $\operatorname{miR}-145^{*}$ & $5 q 32$ & 2 \\
\hline miR-215 & $1 \mathrm{q} 41$ & 6 & miR-145 & $5 q 32$ & 2 \\
\hline miR-744 & $17 p 12$ & 1 & $\operatorname{miR}-31$ & $9 p 21.3$ & 10 \\
\hline miR-195* & 17p13.1 & 1 & $\operatorname{miR}-31^{*}$ & $9 p 21.3$ & 10 \\
\hline miR-451 & $17 q 11.2$ & 1 & $\operatorname{miR}-22$ & $17 p 13.3$ & 3 \\
\hline miR-144 & $17 q 11.2$ & 1 & $\operatorname{miR}-22^{*}$ & $17 p 13.3$ & 3 \\
\hline miR-454 & $17 q 22$ & 1 & miR-503 & $x q 26.3$ & 2 \\
\hline
\end{tabular}

Chr. = Chromosome

miR-100, miR-22, miR-21, miR-574-3p) were significantly under-expressed in xenografts. The expression profiles of 4 miRNAs (miR-31, miR-31*, miR-106b, miR145) were confirmed by RT-PCR.

To evaluate the potential role of the differentially expressed miRNAs, three databases were searched for the known ES-associated genes targeted by these miRNAs, by applying target prediction algorithms. The targets included EWSR1 (GeneID: 2130), FLI1 (GeneID: 2313), SOX2 (GeneID: 6657), p53 (GeneID: 7157), IGFBP3 (GeneID: 3486), IGF1 (GeneID: 3479) and IGF1R (GeneID: 3480). The differential expression of the miRNAs regulating these genes may play a role in the tumorigenesis and tumor progression of ES.

Interestingly, miR-150, which targets the tumor suppressor gene TP53, was expressed in all xenograft samples but in none of the control samples. This is in accordance with the study of Fabbri and colleagues [22] who have included TSGs in their investigation of likely over-expressed miRNA target genes. In addition, one of our xenograft series (Case number 451) showed losses at $17 \mathrm{p}$, containing TP53, that appeared in later passages. Previous ES studies have shown that, despite the low frequency of mutations in TP53, an alteration of TP53, in conjunction with the deletion of $C D K N 2 A$, is associated with a poor clinical outcome [23,24]. Moreover, the homozygous deletion of this gene has been reported in a small subset of ES patients [25,26].

The IGF-1 pathway, whose genes IGF1R, IGF-1 and $I G F B P-3$ are among the target genes of the differentially expressed miRNAs, plays a critical role in cancer development, including ES [26-28]. IGF1R is targeted by miR-145 and miR-31*, and previous studies have show$\mathrm{nIGF1R}$ to be a direct target of miR-145 [29] as well as to be over-expressed in Ewing tumors [27,28]. As for $I G F-1$, it is the target of 11 miRNAs including miR-21, miR-31, miR-145, miR-150, miR-194, miR-215, miR-421,
miR-486-5p, 548c-5p, and miR-873. Interestingly, $I G F B P 3$, which is among the target genes of miR-150*, was, in our study, expressed in all xenografts but not in control samples. IGFBP-3, which is a major regulator of cell proliferation and apoptosis, inhibits the interaction of IGF-1 with its receptor (IGF1R) [30-33]. Indeed, it has been reported that high IGF-1 and low IGFBP-3 levels in serum increase the risk of cancer [26]. IGFBP3 is strongly down-regulated by the EWS/FLI-1 fusion gene [34], which is able to induce expression of embryonic stem cell gene $S O X 2$. Consequently, SOX2 participates in ES cell proliferation and tumorigenesis and might play a central role in ES pathogenesis [35]. As for our study, SOX 2 was among the target genes of miRNA-21 that showed under-expression in xenografts. Another under-expressed miRNA, miR-145, was previously found to target FLII and its increased expression leads to a decreased migration of microvascular cells in response to the growth factor gradients in vitro [36].

Finally, miR-106b targets EWSR1, which undergoes a chromosomal translocation to produce the EWS-FLI fusion gene in a majority of ES cases, where it is commonly considered to trigger the condition. The action of miR-106b is, thus, likely to only impact on the original/ unmodified locus for EWSRI since the EWS-FLI lacks the 3' portion of EWSR1. Further studies would, naturally, be required to confirm this hypothesis.

The alteration of 41 miRNAs was observed in xenograft passages derived from lung metastatic, which may play a crucial role in triggering tumor metastasis. Eight of these miRNAs, all located at the $14 \mathrm{q} 32$ imprinted domain (miR-154\%, miR-337-3P, miR-369-5p, miR-4095p, miR-411, miR-485-3p, miR-487a, miR-770-5p) were not expressed in metastasis xenografts but in control samples, thus suggesting a tumor suppressor function. Interestingly, gastrointestinal stromal tumors (GISTs) have displayed 44 expressed miRNAs originatingfrom 
the $14 \mathrm{q} 32$ chromosomal region, for which the low expression of miRNAs was related to tumor progression [37]. A report by Saito and colleagues [38] suggests that miRNAs located in this region function as tumor repressor genes and changes in the methylation status of their promoters could trigger cancer development. This evidence suggests that the miRNAs identified in our study may act as tumor repressors and their absence could increase the risk of metastasis and tumor progression in ES.

\section{Copy number aberrations in ES xenografts}

The most recurrent copy number alterations detected in our CGH analysis (gains at chromosome 8, 1q and losses at 9 p21.3 and $16 \mathrm{q}$ ) are in agreement with other findings on ES patients [1,39-46]. The crucial role of these changes, gains in 1q, 8 and losses of $9 \mathrm{p} 21.3$ (including loss of $C D K N 2 A$ ) and 16q, has been clarified by notable tumor development and adverse clinical outcome $[42,47,48]$. These copy number changes were seen throughout the whole xenograft series. In all passages of lung metastasis, losses were observed at 1p36.12-pter/ $1 \mathrm{p} 36.21$-pter. Of note, deletion of this site (1p36) has been found to be related to a poor clinical outcome in ES[43,47]. The loss of 1p36.12-pter in the first two passages originating from lung metastasis ( 1 and 4 ) changed to loss of 1 p36.21-pter in the last three passages $(14,21$ and 30). The lung metastasis xenografts showed 9 copy number changes, whereas only 3 of these aberrations were observable in the xenograft passages from its primary tumor. Likewise in many tumors during the disease progression, the increase of genomic instability is also seen here. This instability most probably explains the variation of the size of $1 \mathrm{p}$ deletion. The fact that the terminal part is retained in the deletion emphasizes the importance of $1 \mathrm{p} 36.21$-pter region in the selection and in the disease progression.

Somatic mosaicism/heterogeneity occurs commonly in tumors and plays an important role in the progression of the tumor and, thereby, can also explain why some xenograft passages show copy number changes and others do not.

\section{Integration of miRNA expression profiles and DNA copy number changes}

DNA copy number abnormalities can have a direct impact on miRNA expression [49]. In the current study, 20 differentially expressed miRNAs were located in the copy number altered regions. These findings are in accordance with Calin et al. (2004) who observed that half of the miRNAs are located in cancer-associated regions of chromosomes as well as in genomic regions frequently amplified or lost in cancer [49]. The target genes for many of the changes are still unknown and, therefore, miRNAs could well be considered to be the drivers of the underlying changes.

MiR-31 and miR-31*, targeting IGF1 and IGF1R, are located at the frequently deleted region of $9 \mathrm{p} 21.3$, containing the CDKN2A gene, which was frequently lost in our samples. Under-expression of miR-31 or deletion of the miR-31 genomic locus is also found in human breast cancers. This miRNA regulates metastasis by opposing local invasion and metastatic colonization in this cancer [50-52]. Chromosome 1 gain is a frequent gain that contains the whole chromosome and seems to be poor prognostic sign [53]. Interestingly, in our study five overexpressed miRNAs (miR-765, miR-135b, miR29c, miR-215, and miR-557) (Table 6) were associated to 1q gain. These candidate miRNAs have an important role and could explain the underlying mechanism in ES. Nevertheless, functional validations of the predicted target genes are needed to better understand their role in the ES tumorgnesis.

\section{Conclusions}

The current study provides new information about the miRNA expression and its relationship with the associated genomic copy number changes in ES xenografts. Our findings suggest that miRNAs play a role in the molecular pathogenesis and tumorigenesis of ES by regulating important genes in the IGF1 pathway as well as the genes FLI1, EWSR1, and the EWS-FLI1 fusion gene. In addition, integration of the data for gene copy number changes and miRNA profiles demonstrated some cases where the differential expression of miRNAs was the result of copy number alteration of the miRNA genomic locus. Moreover, our study showed that the xenografts can reflect well the genomic pattern of their original tumor.

\section{Acknowledgements}

The study was supported by grants from European Commission (EuroBoNeT Project LSHC-CT-2006-018814) and the special state subsidy research funds appropriated to the Helsinki and Uusimaa Hospital District (HUS EVO).

\section{Author details}

${ }^{1}$ Department of Pathology, Haartman Institute and HUSLAB, University of Helsinki and Helsinki University Central Hospital, Helsinki, Finland.

${ }^{2}$ Department of Information and Computer Science, Aalto University School of Science and Technology, Espoo, Finland. ${ }^{3}$ Department of Pathology, Universitat de Valencia Studi General, Valencia, Spain. ${ }^{4}$ Laboratorio di Ricerca Oncologica, Istituto Ortopedico Rizzoli, Bologna, Italy. ${ }^{5}$ Laboratory of Molecular Biology, Fundación Instituto Valenciano de Oncología, Valencia, Spain.

\section{Authors' contributions}

NM and MG have equally contributed to this study. SK, as a senior researcher, designed the study and participated in writing the manuscript. NM performed the laboratory work and participated in writing. SS and TN performed the array CGH analysis and contributed to the design of the study plan. MG participated in writing. GL participated in designing the statistical analysis and preparing the manuscript. EE, US-P, M-LK-J and AR 
participated in designing the study and provided clinical data. All authors contributed to the manuscript and approved the final version of it.

\section{Competing interests}

The authors declare that they have no competing interests.

Received: 18 January 2012 Accepted: 20 March 2012

Published: 20 March 2012

\section{References}

1. Savola S, Klami A, Tripathi A, Niini T, Serra M, Picci P, Kaski S, Zambelli D Scotlandi K, Knuutila S: Combined use of expression and CGH arrays pinpoints novel candidate genes in Ewing sarcoma family of tumors. BMC Cancer 2009, 9:17.

2. Bogner PN, Patnaik SK, Pitoniak R, Kannisto E, Repasky E, Hylander B, Yendamuri S, Ramnath N: Lung cancer xenografting alters microRNA profile but not immunophenotype. Biochem Biophys Res Commun 2009, 386:305-310

3. Mayordomo E, Machado I, Giner F, Kresse SH, Myklebost O, Carda C, Navarro S, Llombart-Bosch A: A Tissue Microarray Study of Osteosarcoma: Histopathologic and Immunohistochemical Validation of Xenotransplanted Tumors as Preclinical Models. Appl Immunohistochem Mol Morphol 2010, 18:453-461.

4. El-Rifai W, Harper JC, Cummings OW, Hyytinen ER, Frierson HF Jr, Knuutila S, Powell SM: Consistent genetic alterations in xenografts of proximal stomach and gastro-esophageal junction adenocarcinomas. Cancer Res 1998, 58:34-37.

5. Neale G, Su X, Morton CL, Phelps D, Gorlick R, Lock RB, Reynolds CP, Maris JM, Friedman HS, Dome J, Khoury J, Triche TJ, Seeger RC, Gilbertson R, Khan J, Smith MA, Houghton PJ: Molecular characterization of the pediatric preclinical testing panel. Clin Cancer Res 2008, 14:4572-4583

6. Whiteford CC, Bilke S, Greer BT, Chen Q, Braunschweig TA, Cenacchi N, Wei JS, Smith MA, Houghton P, Morton C, Reynolds CP, Lock R, Gorlick R, Khanna C, Thiele CJ, Takikita M, Catchpoole D, Hewitt SM, Khan J: Credentialing preclinical pediatric xenograft models using gene expression and tissue microarray analysis. Cancer Res 2007, 67:32-40.

7. Hahn SA, Seymour AB, Hoque AT, Schutte M, da Costa LT, Redston MS, Caldas C, Weinstein CL, Fischer A, Yeo CJ: Allelotype of pancreatic adenocarcinoma using xenograft enrichment. Cancer Res 1995, 55:4670-4675

8. Fichtner I, Rolff J, Soong R, Hoffmann J, Hammer S, Sommer A, Becker M, Merk J: Establishment of patient-derived non-small cell lung cancer xenografts as models for the identification of predictive biomarkers. Clin Cancer Res 2008, 14:6456-6468.

9. Perez-Soler R, Kemp B, Wu QP, Mao L, Gomez J, Zeleniuch-Jacquotte A, Yee $\mathrm{H}$, Lee JS, Jagirdar J, Ling YH: Response and determinants of sensitivity to paclitaxel in human non-small cell lung cancer tumors heterotransplanted in nude mice. Clin Cancer Res 2000, 6:4932-4938.

10. Bartels CL, Tsongalis GJ: MicroRNAs: novel biomarkers for human cancer. Clin Chem 2009, 55:623-631.

11. Winter J, Jung S, Keller S, Gregory RI, Diederichs S: Many roads to maturity: microRNA biogenesis pathways and their regulation. Nat Cell Biol 2009, 11:228-234.

12. Lu M, Zhang Q, Deng M, Miao J, Guo Y, Gao W, Cui Q: An analysis of human microRNA and disease associations. PLoS One 2008, 3:e3420.

13. Riggi N, Cironi L, Provero P, Suva ML, Kaloulis K, Garcia-Echeverria C, Hoffmann F, Trumpp A, Stamenkovic I: Development of Ewing's sarcoma from primary bone marrow-derived mesenchymal progenitor cells. Cancer Res 2005, 65:11459-11468.

14. Castillero-Trejo $Y$, Eliazer $S$, Xiang $L$, Richardson JA, llaria RL Jr: Expression of the EWS/FLI-1 oncogene in murine primary bone-derived cells Results in EWS/FLI-1-dependent, ewing sarcoma-like tumors. Cancer Res 2005, 65:8698-8705.

15. Tirode F, Laud-Duval K, Prieur A, Delorme B, Charbord P, Delattre O: Mesenchymal stem cell features of Ewing tumors. Cancer Cell 2007, 11:421-429.

16. Potikyan G, France KA, Carlson MR, Dong J, Nelson SF, Denny CT: Genetically defined EWS/FLI1 model system suggests mesenchymal origin of Ewing's family tumors. Lab Invest 2008, 88:1291-1302.
17. Riggi N, Suva ML, Stamenkovic l: Ewing's sarcoma origin: from duel to duality. Expert Rev Anticancer Ther 2009, 9:1025-1030.

18. Richter GH, Plehm S, Fasan A, Rossler S, Unland R, Bennani-Baiti IM, Hotfilder M, Lowel D, von Luettichau I, Mossbrugger I, QuintanillaMartinez L, Kovar H, Staege MS, Muller-Tidow C, Burdach S: EZH2 is a mediator of EWS/FLI1 driven tumor growth and metastasis blocking endothelial and neuro-ectodermal differentiation. Proc Natl Acad Sci USA 2009, 106:5324-5329.

19. von Levetzow C, Jiang X, Gwye Y, von Levetzow G, Hung L, Cooper A Hsu JH, Lawlor ER: Modeling initiation of Ewing sarcoma in human neural crest cells. PLoS One 2011, 6:e19305.

20. Nakatani F, Ferracin M, Manara MC, Ventura S, Del Monaco V, Ferrari S, Alberghini M, Grilli A, Knuutila S, Schaefer KL, Mattia G, Negrini M, Picci P, Serra M, Scotlandi K: miR-34a predicts survival of Ewing's sarcoma patients and directly influences cell chemosensitivity and malignancy. $J$ Pathol 2012, 226:796-805.

21. Ban J, Jug G, Mestdagh P, Schwentner R, Kauer M, Aryee DN, Schaefer KL, Nakatani F, Scotlandi K, Reiter M, Strunk D, Speleman F, Vandesompele J, Kovar H: Hsa-mir-145 is the top EWS-FLI1-repressed microRNA involved in a positive feedback loop in Ewing's sarcoma. Oncogene 2011, 30:2173-2180

22. Fabbri M, Croce CM, Calin GA: MicroRNAs. Cancer J 2008, 14:1-6.

23. de Alava E, Antonescu CR, Panizo A, Leung D, Meyers PA, Huvos AG, PardoMindan FJ, Healey JH, Ladanyi M: Prognostic impact of P53 status in Ewing sarcoma. Cancer 2000, 89:783-792.

24. Huang HY, Illei PB, Zhao Z, Mazumdar M, Huvos AG, Healey JH, Wexler LH, Gorlick R, Meyers P, Ladanyi M: Ewing sarcomas with p53 mutation or p16/p14ARF homozygous deletion: a highly lethal subset associated with poor chemoresponse. J Clin Oncol 2005, 23:548-558.

25. Park YK, Chi SG, Kim YW, Park HR, Unni KK: P53 mutations in Ewing's sarcoma. Oncol Rep 2001, 8:533-537.

26. Cohen $\mathrm{P}$, Clemmons DR, Rosenfeld RG: Does the GH-IGF axis play a role in cancer pathogenesis? Growth Horm IGF Res 2000, 10:297-305.

27. Sekyi-Otu A, Bell RS, Ohashi C, Pollak M, Andrulis IL: Insulin-like growth factor 1 (IGF-1) receptors, IGF-1, and IGF-2 are expressed in primary human sarcomas. Cancer Res 1995, 55:129-134.

28. Valentinis B, Baserga R: IGF-I receptor signalling in transformation and differentiation. Mol Pathol 2001, 54:133-137.

29. La Rocca G, Badin M, Shi B, Xu SQ, Deangelis T, Sepp-Lorenzinoi L, Baserga R: Mechanism of growth inhibition by MicroRNA 145: the role of the IGF-I receptor signaling pathway. J Cell Physiol 2009, 220:485-491.

30. Cohen P, Lamson G, Okajima T, Rosenfeld RG: Transfection of the human insulin-like growth factor binding protein-3 gene into Balb/c fibroblasts inhibits cellular growth. Mol Endocrinol 1993, 7:380-386.

31. Rajah $\mathrm{R}$, Valentinis $\mathrm{B}$, Cohen $\mathrm{P}$ : Insulin-like growth factor (IGF)-binding protein-3 induces apoptosis and mediates the effects of transforming growth factor-beta1 on programmed cell death through a p53- and IGFindependent mechanism. J Biol Chem 1997, 272:12181-12188.

32. Schedlich LJ, Young TF, Firth SM, Baxter RC: Insulin-like growth factorbinding protein (IGFBP)-3 and IGFBP-5 share a common nuclear transport pathway in T47D human breast carcinoma cells. J Biol Chem 1998, 273:18347-18352.

33. Singh B, Charkowicz D, Mascarenhas D: Insulin-like growth factorindependent effects mediated by a C-terminal metal-binding domain of insulin-like growth factor binding protein-3. J Biol Chem 2004 279:477-487.

34. Prieur A, Tirode F, Cohen P, Delattre O: EWS/FLI-1 silencing and gene profiling of Ewing cells reveal downstream oncogenic pathways and a crucial role for repression of insulin-like growth factor binding protein 3 . Mol Cell Biol 2004, 24:7275-7283.

35. Riggi N, Suva ML, De Vito C, Provero P, Stehle JC, Baumer K, Cironi L, Janiszewska M, Petricevic T, Suva D, Tercier S, Joseph JM, Guillou L, Stamenkovic I: EWS-FLI-1 modulates miRNA145 and SOX2 expression to initiate mesenchymal stem cell reprogramming toward Ewing sarcoma cancer stem cells. Genes Dev 2010, 24:916-932.

36. Larsson E, Fredlund Fuchs P, Heldin J, Barkefors I, Bondjers C, Genove G, Arrondel C, Gerwins P, Kurschat C, Schermer B, Benzing T, Harvey SJ, Kreuger J, Lindahl P: Discovery of microvascular miRNAs using public gene expression data: miR-145 is expressed in pericytes and is a regulator of Fli1. Genome Med 2009, 1:108. 
37. Haller F, von Heydebreck A, Zhang JD, Gunawan B, Langer C, Ramadori G, Wiemann S, Sahin O: Localization- and mutation-dependent microRNA (miRNA) expression signatures in gastrointestinal stromal tumours (GISTs), with a cluster of co-expressed miRNAs located at 14q32.31. J Pathol 2010, 220:71-86.

38. Saito Y, Liang G, Egger G, Friedman JM, Chuang JC, Coetzee GA, Jones PA: Specific activation of microRNA-127 with downregulation of the protooncogene BCL6 by chromatin-modifying drugs in human cancer cells. Cancer Cell 2006, 9:435-443.

39. Armengol G, Tarkkanen M, Virolainen M, Forus A, Valle J, Bohling T, AskoSeljavaara S, Blomqvist C, Elomaa I, Karaharju E, Kivioja AH, Siimes MA, Tukiainen E, Caballin MR, Myklebost O, Knuutila S: Recurrent gains of 1q, 8 and 12 in the Ewing family of tumours by comparative genomic hybridization. Br J Cancer 1997, 75:1403-1409.

40. Tarkkanen M, Kiuru-Kuhlefelt S, Blomqvist C, Armengol G, Bohling T, Ekfors T, Virolainen M, Lindholm P, Monge O, Picci P, Knuutila S, Elomaa I: Clinical correlations of genetic changes by comparative genomic hybridization in Ewing sarcoma and related tumors. Cancer Genet Cytogenet 1999, 114:35-41.

41. Brisset S, Schleiermacher G, Peter M, Mairal A, Oberlin O, Delattre O, Aurias A: CGH analysis of secondary genetic changes in Ewing tumors: correlation with metastatic disease in a series of 43 cases. Cancer Genet Cytogenet 2001, 130:57-61.

42. Ozaki T, Paulussen M, Poremba C, Brinkschmidt C, Rerin J, Ahrens S, Hoffmann C, Hillmann A, Wai D, Schaefer KL, Boecker W, Juergens $H_{\text {, }}$ Winkelmann W, Dockhorn-Dworniczak B: Genetic imbalances revealed by comparative genomic hybridization in Ewing tumors. Genes Chromosomes Cancer 2001, 32:164-171.

43. Lopez-Guerrero JA, Machado I, Scotlandi K, Noguera R, Pellin A, Navarro S, Serra M, Calabuig-Farinas S, Picci P, Llombart-Bosch A: Clinicopathological significance of cell cycle regulation markers in a large series of genetically confirmed Ewing's Sarcoma Family of Tumors. Int I Cancer 2011, 128:1139-1150.

44. Lopez-Guerrero JA, Pellin A, Noguera R, Carda C, Llombart-Bosch A: Molecular analysis of the 9p21 locus and p53 genes in Ewing family tumors. Lab Invest 2001, 81:803-814

45. Amiel A, Ohali A, Fejgin M, Sardos-Albertini F, Bouaron N, Cohen IJ, Yaniv I, Zaizov R, Avigad S: Molecular cytogenetic parameters in Ewing sarcoma. Cancer Genet Cytogenet 2003, 140:107-112

46. Ferreira Bl, Alonso J, Carrillo J, Acquadro F, Largo C, Suela J, Teixeira MR, Cerveira N, Molares A, Gomez-Lopez G, Pestana A, Sastre A, Garcia-Miguel P, Cigudosa JC: Array CGH and gene-expression profiling reveals distinct genomic instability patterns associated with DNA repair and cell-cycle checkpoint pathways in Ewing's sarcoma. Oncogene 2008, 27:2084-2090.

47. Hattinger CM, Rumpler S, StrehI S, Ambros IM, Zoubek A, Potschger U, Gadner H, Ambros PF: Prognostic impact of deletions at 1p36 and numerical aberrations in Ewing tumors. Genes Chromosomes Cancer 1999, 24:243-254.

48. Huang HY, Illei PB, Zhao Z, Mazumdar M, Huvos AG, Healey JH, Wexler LH, Gorlick R, Meyers P, Ladanyi M: Ewing sarcomas with p53 mutation or p16/p14ARF homozygous deletion: a highly lethal subset associated with poor chemoresponse. J Clin Oncol 2005, 23:548-558.

49. Calin GA, Sevignani C, Dumitru CD, Hyslop T, Noch E, Yendamuri S, Shimizu M, Rattan S, Bullrich F, Negrini M, Croce CM: Human microRNA genes are frequently located at fragile sites and genomic regions involved in cancers. Proc Natl Acad Sci USA 2004, 101:2999-3004.

50. Zhang L, Huang J, Yang N, Greshock J, Megraw MS, Giannakakis A, Liang S, Naylor TL, Barchetti A, Ward MR, Yao G, Medina A, O'brien-Jenkins A, Katsaros D, Hatzigeorgiou A, Gimotty PA, Weber BL, Coukos G: microRNAs exhibit high frequency genomic alterations in human cancer. Proc Natl Acad Sci USA 2006, 103:9136-9141.

51. Yan LX, Huang XF, Shao Q, Huang MY, Deng L, Wu QL, Zeng YX, Shao JY: MicroRNA miR-21 overexpression in human breast cancer is associated with advanced clinical stage, lymph node metastasis and patient poor prognosis. RNA 2008, 14:2348-2360.

52. Valastyan S, Reinhardt F, Benaich N, Calogrias D, Szasz AM, Wang ZC, Brock JE, Richardson AL, Weinberg RA: A pleiotropically acting microRNA miR-31, inhibits breast cancer metastasis. Cell 2009, 137:1032-1046.

53. Mackintosh C, Ordonez JL, Garcia-Dominguez DJ, Sevillano V, LlombartBosch A, Szuhai K, Scotlandi K, Alberghini M, Sciot R, Sinnaeve F, Hogendoorn PC, Picci P, Knuutila S, Dirksen U, Debiec-Rychter M,
Schaefer KL, de Alava E: 1q gain and CDT2 overexpression underlie an aggressive and highly proliferative form of Ewing sarcoma. Oncogene 2011, 31:1287-1298.

doi:10.1186/1756-9966-31-24

Cite this article as: Mosakhani et al:: An integrated analysis of miRNA and gene copy numbers in xenografts of Ewing's sarcoma. Journal of Experimental \& Clinical Cancer Research 2012 31:24.

\section{Submit your next manuscript to BioMed Central and take full advantage of:}

- Convenient online submission

- Thorough peer review

- No space constraints or color figure charges

- Immediate publication on acceptance

- Inclusion in PubMed, CAS, Scopus and Google Scholar

- Research which is freely available for redistribution

Submit your manuscript at www.biomedcentral.com/submit
Biomed Central 